Velasco-Arboleda, J.A. (2018). La producción del espacio: relaciones entre la ciudad edificada y los practicantes de parkour en Cali.Revista de Antropología y Sociología: VIRAJES, 20(2), 125-144. DOI: 10.17151/rasv.2018.20.2.7.

\title{
La producción del espacio: relaciones entre la ciudad edificada y los practicantes de parkour en Cali*
}

JONNY ANDRÉS VELASCO-ARBOLEDA**

Recibido: 16 de abril de 2018

Aprobado: 15 de junio de 2018

Artículo de Investigación

\footnotetext{
* Artículo de investigación: Presenta los resultados del trabajo de maestría en sociología titulado "Cuerpos y Trazos en el Lienzo Urbano: La Práctica del Parkour en Cali", realizado con el apoyo del Grupo de Investigación Acción Colectiva y Cambio Social de la Universidad del Valle.

** Profesional en Recreación y Magíster en Sociología de la Universidad del Valle. Profesor de la misma universidad en el Instituto de Educación y Pedagogía. Es integrante de la línea de investigación recreación, intersubjetividades e interculturalidad adscrita al Grupo de Investigación de Educación Popular de la Universidad del Valle. Universidad del Valle, Cali-Colombia. E-mail: jonny.velasco@

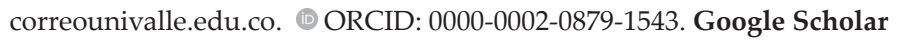




\title{
Resumen
}

El artículo da cuenta de la relación que establecen los practicantes de parkour con el espacio público de la ciudad de Cali. El espacio es asumido como el resultado de la acción social que lo produce desde las representaciones, percepciones, vivencias, usos, significados, símbolos. Por ello, se realizó un acercamiento etnográfico desde la trialéctica espacial propuesta por Lefebvre (2013) a cinco escenarios de Cali, en los cuales jóvenes realizan parkour; complementando con observación participante, notas de campo, entrevistas, consulta de páginas virtuales oficiales de los grupos y fotografías. Al finalizar, se sugiere que el espacio urbano es un escenario ilimitado de acción y experiencias de libertades individuales y colectivas que propician una tensión entre el diseño urbanístico y los usos emergentes que se hacen del espacio público.

Palabras clave: parkour, sociología urbana, etnografía, producción del espacio.

\section{The production of space: relations between the built city and parkourists in Cali}

\begin{abstract}
The article gives an account of the relationship established by Parkourists with the public space of the city of Cali. The space is assumed as the result of the social action that produces it from representations, perceptions, experiences, uses, meanings, and symbols. For this reason, an ethnographic approach was carried out from the trialogical space proposed by Lefebvre (2013) to five scenarios of the city of Cali, in which young people perform parkour, complemented with participant observation, field notes, interviews, consultation of official virtual pages of the groups and photographs. At the end, it is suggested that the urban space is an unlimited scenario of action and experiences of individual and collective freedoms that foster a tension between urban design and the emerging uses that are made of the public space.
\end{abstract}

Key words: parkour, urban sociology, ethnography, space production. 


\section{Introducción}

T a ciudad ha sido campo de interés para diversos investigadores y sociólogos en diferentes épocas, tales como Simmel (2002), Park (1999), Wirth (1938), Lefebvre (1972, 2013), Joseph (1988a, 1999a, 1999b), Hannerz (1986), entre otros, porque presenta múltiples interacciones y usos del espacio que convergen en ella. En este sentido, es importante contribuir a los estudios de la vida urbana, para comprender por qué el espacio es el resultado de prácticas y relaciones. Experiencias de la acción social que lo producen desde las representaciones, percepciones, vivencias, usos, significados y símbolos. El presente documento elabora un análisis preliminar de la práctica conocida como parkour, que consiste en el desplazamiento por la arquitectura urbana de manera efectiva y eficiente usando únicamente el cuerpo humano. Esta pone en tensión el diseño urbanístico y los usos emergentes que se hacen del espacio público, un tema contemporáneo relevante en lo que respecta a la comprensión de la ciudad y las nuevas formas de habitarla, teniendo en cuenta que el uso de los espacios públicos es una cuestión central en la vida de cualquier ciudadano.

La importancia de esta investigación se centró en la elaboración de una etnografía urbana de espacios públicos de Cali en los que jóvenes realizan parkour, práctica que no es autóctona de Colombia pero que "ha tomado fuerza a partir de narrativas en medios masivos de comunicación $\mathrm{y}$ en redes sociales a partir de videos en los que practicantes de todo el mundo exploran la ciudad con diversas apropiaciones espaciales" (Leyden, 2013, p. 42).

Elartículo toma como basela trialéctica espacial propuesta por Lefebvre (2013) - espacio percibido, espacio concebido, espacio vivido-, la noción de descripción densa (Geertz, 1973) y el enfoque microsociológico de Goffman (1979) aplicado a los contextos urbanos. El objetivo es comprender la relación que establecen los practicantes de parkour con el espacio público de Cali, porque problematizan la idea de que, en las construcciones arquitectónicas al estar preestablecidas funcionalmente, la vida cotidiana solo tiene lugar a partir del conjunto de normas y ordenaciones de comportamiento implícitas a la vida pública en la que las personas coexisten. No obstante, hacen un uso alternativo del espacio público logrando impregnarlo de significados, símbolos y cristalizaciones al punto de concebir el espacio funcional como un espacio de vida.

Respecto a lo metodológico, se elaboró una descripción de cinco escenarios de Cali, en los cuales se realiza la práctica abarcando las tres 
dimensiones del espacio, con el propósito de dar cuenta de cómo se está produciendo la trialéctica propuesta por Lefebvre (2013). Los espacios fueron la Unidad Deportiva Alberto Galindo, situada en la comuna 19, en la que se encuentran dos sub espacios: el Muro de Parkour Cali, que se ubica en el exterior en una zona verde y la Liga de Gimnasia Vallecaucana, la cual está dentro del Coliseo El Pueblo, escenario cubierto; el Parque de los Estudiantes o "Jovita", escenario ubicado en la comuna 3; el parque 1 de mayo situado en la comuna 17; el coliseo Alberto León Betancourt, escenario localizado en el complejo deportivo de la Universidad del Valle, sede Meléndez, comuna 22 y el Museo la Tertulia que se encuentra en la comuna 3. El trabajo de campo se realizó durante los eventos y entrenamientos programados por los practicantes, se participó en dos ocasiones del entreno masivo, realizado en el Parque 1 de Mayo. Anualmente en el mes de marzo durante los años 2016 y 2017; y el encuentro anual nacional de practicantes llamado Ajisie, el cual usa varios espacios de la ciudad y se realizó en diciembre del 2016. Además, se asistió a entrenamientos de los grupos Sifakas, Team Motion y Wild Street, en el periodo de marzo a julio del 2017. Las fuentes utilizadas fueron: la observación participante, permitiendo que el cuerpo del investigador fuese el medio para un primer punto de análisis y una herramienta para la investigación, porque "para comprender los tres momentos del espacio social, podemos remitirnos al cuerpo" (Lefebvre, 2013, p. 98). Asimismo, la información se complementó con notas de campo, entrevistas etnográficas (Guber, 2011), consulta de páginas virtuales oficiales de los grupos y fotografías. El análisis se hizo desde la lectura personal, al vivenciar el parkour, describir las situaciones observadas y las narraciones contadas por los practicantes.

En el desarrollo de la investigación se cambió el orden en que Lefebvre (2013) organizó los tres componentes de su trialéctica espacial, de la siguiente manera: iniciando con el espacio concebido, porque permitió ubicar al investigador con la ordenación urbanística; desde los referentes de normatividad y reglamentación, procurando identificar, describir y clasificar el espacio público desde los propósitos que se pretenden desde el gobierno local, que define unas normas, signos, códigos de ordenación, fragmentación y restricción. Posteriormente, se pasó al espacio percibido teniendo en cuenta que es la relación que se tiene con la infraestructura de la ciudad y las maneras de usarla, a partir de los recorridos realizados, que corresponden a lo urbano y encuentran cierta sensibilidad por la morfología de los lugares, recorriéndolos en gran parte desde la manera vivencial en la experiencia empírica del Parkour, dado que se practica el espacio al percibir su composición, su esencia, sus formas y sus usos en la cotidianidad. Finalmente, se revisó el espacio vivido, que los practicantes 
de Parkour o trazadores, como se hacen llamar, cargan de significados y sentidos, siendo importante los usos in situ, imágenes, videos y formas de narrar el espacio urbano.

El artículo desarrolla los siguientes asuntos: en la primera parte expone la perspectiva del espacio público desde lo concebido y su funcionalidad implícita, la cual es transformada desde los usos, logrando que el espacio percibido emerja en las interacciones a partir de los recursos y expresiones del parkour; en la sección sucesiva se hace una aproximación al espacio vivido, considerando que los practicantes en la espontaneidad y creatividad de los desplazamientos que realizan en la ciudad, apropian el espacio público y lo reestructuran constantemente. En el último apartado se sugiere que la apropiación física y simbólica de algunos escenarios de la ciudad, propiciada desde la práctica, logra transformaciones en la percepción, haciendo que se perciban como seguros para la comunidad aledaña. Las consideraciones presentadas constituyen un conjunto de reflexiones iniciales sobre el parkour y la trialéctica espacial propuesta por Lefebvre (2013). Se espera que puedan ser útiles para trabajos futuros, abierto a lectores sociólogos y aquellos de otras disciplinas de las ciencias sociales, para que estos independientemente de su formación sean quienes validen la pertinencia.

\section{La configuración espacial urbana y la re-configuración espacial en el Parkour}

Se puede apuntar que el espacio arquitectónico y urbanístico en la modernidad tiende hacia ese carácter homogéneo: lugar dela confusión y de la fusión entre lo geométrico y lo visual, que engendra un malestar físico. Todo se parece. Ya no hay localización ni lateralización. Los significantes y significados, las marcas, los indicadores se añaden después como decorado. Lo que refuerza la impresión desértica y el malestar. (Lefebvre, 2013, p. 245)

Esta cita inicial nos permite sugerir que existe un "decorado" que conforma a los cinco escenarios analizados y lleva consigo una ideología que estructura el orden urbano, de acuerdo con algunos parámetros de tipo político y económico impuestos por los agentes productores la ciudad concebida. En los recorridos se reconocieron los diferentes y diversos elementos "físicos" que componen, lo que el MECEP (2010) considera espacio público desde la perspectiva de normatividad y reglamentación, que para Lefebvre (2013) es el espacio concebido. Esto es, las observaciones de campo tenían el objetivo de plasmar la operacionalización de la categoría 
a partir de: a) la concepción espacial de orden urbanístico, reflejada en la conformación del área o zona que aloja el escenario y en la arquitectura de los edificios o construcciones; b) los símbolos, signos, señales y objetos que determinan los usos del espacio, como es el caso de las señales de tráfico urbano, las canecas públicas de reciclaje de basura, entre otras; c) los dispositivos de control del espacio que se reflejan en la presencia de cámaras de vigilancia, el personal de seguridad y los avisos que sancionan el mal uso.

Esto permitió reconocer que cada uno de los escenarios analizados está pensado para ser un bien público colectivo, y supone que en su uso los ciudadanos deben tener cierto cuidado para que se garantice su permanencia en el tiempo, además su construcción fue pensada desde un criterio funcional a la ciudad. Por ello, encontramos que cada estructura física (parque, museo, plaza, complejo deportivo, coliseo universitario, etc.) cumple con un propósito enmarcado desde su concepción y posterior construcción

Cabe indicar que no es sólo la arquitectura, sino el propio espacio público el que ofrece una fuerte imposición de los usos suscitados en el espacio percibido, dado que cada escenario fue pensado desde una perspectiva funcional. Se sugiere entonces que lo concebido inscribe categorías sociales, como las identificadas en el Coliseo El Pueblo, escenario deportivo usado principalmente para el baloncesto y sede de las ligas vallecaucanas de tenis de mesa, gimnasia, lucha, taekwondo, esgrima, judo, entre otros. Su "decorado" es pensado para la práctica de disciplinas consideradas deportes de alto rendimiento y aunque recientemente se han construido espacios físicos para otras prácticas emergentes o informales (Lebreton, Routier y Pardo, 2012) como el skateboarding y el parkour, no son legitimadas como deportes. También se reconoce un decorado puntual en el Museo La Tertulia, que fue pensado como un espacio propicio para la cultura y es reconocido porque en sus salas hay una actividad constante de exposiciones de arte moderno y contemporáneo. Es decir, como espacios concebidos tienen una intención simbólica, al respecto Balandier (1994) menciona:

Toda ciudad se va enriqueciendo, a lo largo de su historia, de estos lugares a los que puede serles atribuida una función simbólica, que reciben de manos del destino o que obtienen de los acontecimientos (...) Ciertos sitios expresan el poder, imponen su sacralidad, mejor de lo que podría hacerlo cualquier explicación. (p. 26) 
En los dos escenarios indicados es posible reconocer la imposición simbólica desde lo que ofrece la arquitectura, pese a que como se mencionó en el párrafo anterior el espacio público por sí solo fomenta usos en el espacio practicado. Esto es visible en los recorridos realizados por los demás escenarios en los que se practica parkour, se evidencia que desde el poder municipal se piensan diferentes dispositivos para el control de los cuerpos, como los pasajes del Parque de los estudiantes "Jovita", el exterior del Coliseo de la Universidad del Valle y el Complejo Deportivo Alberto Galindo, zonas pensadas para favorecer la movilidad y por ello tienen falta de asientos; en contraste con el Parque 1 de Mayo y el Museo La Tertulia, escenarios en los que su alrededor tienen mobiliario público para el descanso, también se identificó en el museo la presencia de cámaras de vigilancia y seguridad privada. Además, se evidenció la ordenanza cívica, en algunos letreros encontrados en el Parque 1 de Mayo y dentro de la Liga de Gimnasia, los cuales indican cómo hacer un uso adecuado de los espacios, evitando arrojar basuras, cuidar de los bienes ajenos y procurar levantar las heces de las mascotas. Existe entonces la intención de guiar a los ciudadanos en la manera adecuada de practicar la ciudad (foto 1).

Como corolario de lo mencionado, Bourdieu (1999) enuncia la imbricación simbólica entre el espacio concebido y la práctica espacial de la siguiente manera:

El espacio es uno de los lugares donde se afirma y ejerce el poder, y sin duda en la forma más sutil, la de la violencia simbólica como violencia inadvertida: los espacios arquitectónicos (...) son en verdad los componentes más importantes, a causa de su misma invisibilidad (...) de la simbólica del poder y de los efectos totalmente reales del poder simbólico. (p. 122) 


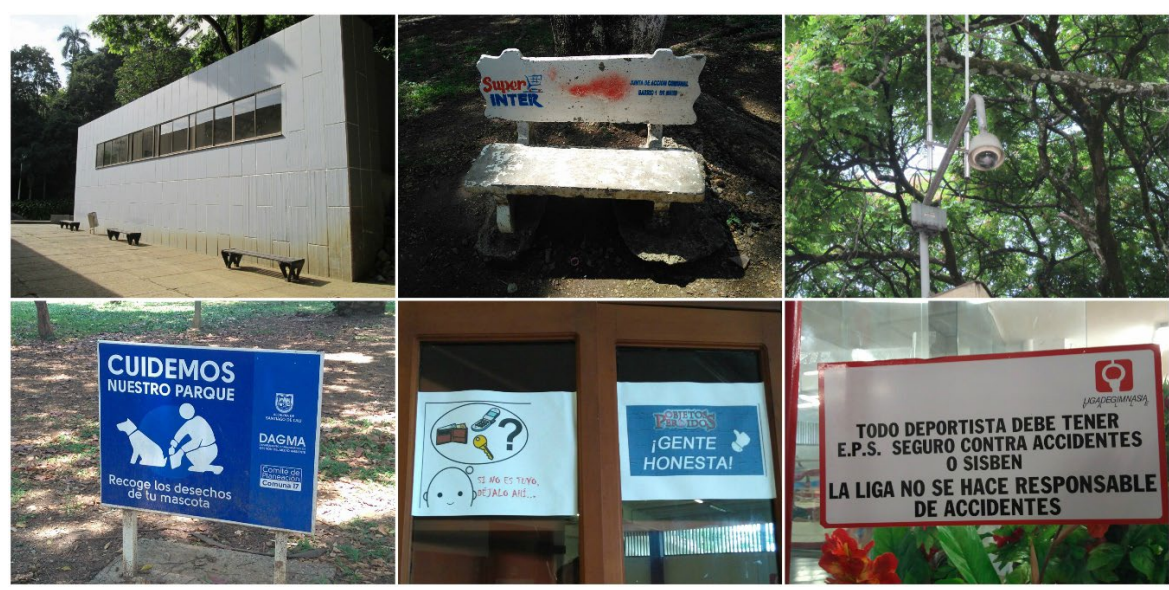

Foto 1. Espacio Concebido Fuente: el autor

Entonces, el primer hallazgo tiene que ver con que a pesar de que no se puede desconocer que hay una implantación simbólica en la planificación urbanística que se hace de la ciudad, los usuarios y trazadores recurren a diversos recursos y expresiones en el espacio urbano. A saber, el espacio percibido se configura de un orden de interacción (Goffman, 1991). Para operacionalizar la categoría de lo percibido se consideraron importantes las formas materiales del espacio urbano y la percepción de los sentidos para comprender los escenarios y lo que estos propician, desde la sensibilidad por la morfología y su relación con el uso vivencial o funcional coherente, es decir, lo percibido se reconoce a partir de la experiencia empírica porque se practica el espacio al percibir su composición, su esencia, sus formas y sus usos en la cotidianidad. Este tipo de orden social se establece en el plano de la interacción y abarca los comportamientos relacionados con la perspectiva formal que sugiere la ciudad construida. En palabras de Lefebvre (2013): "Lo que concierne al espacio social y a la relación con el espacio de cada miembro de una sociedad determinada, esta cohesión implica a la vez un nivel de competencia y un grado específico de performance" (p. 92).

Se pueden encontrar diversos comportamientos realizados por los ciudadanos, en los casos observados en el trabajo de campo. El coliseo Alberto León Betancourt se usa para hacer actividades y reuniones que no están relacionadas con lo deportivo, como presentaciones sociales y culturales; algunos espacios del Museo La Tertulia y el Parque de los estudiantes "Jovita" son usados para el consumo de bebidas alcohólicas o sustancias psicoactivas por algunos adolescentes; la Liga de Gimnasia 
ha permitido la inclusión de prácticas como el Pole Dance, entre otras. De esta manera se hace visible la "pugna" entre la funcionalidad concebida y el uso que es atribuido por los ciudadanos, el cual generalmente está en tensión entre el diseño urbanístico y lo que se considera urbano. En esta lógica de performance, se evidenció que los trazadores logran una suerte de deformación a partir del uso de los espacios de la ciudad, favoreciendo la posibilidad de recorrerlos de manera alternativa desde la agencia y el actuar libremente. En el siguiente párrafo se da entrada a esta idea, a partir de notas de campo:

El 19 de febrero en un entrenamiento, en el Coliseo, se nos indicó que aquellos que sabían hacer algunos movimientos de parkour los realizaríamos en un recorrido sobrepasando unos obstáculos de llantas, como mínimo se debían realizar dos trazos diferentes por obstáculo. Mi destreza física y acercamiento a la práctica me permitió sobrepasar las llantas, haciendo sutilmente los movimientos con los que me familiarizaba. Posteriormente, el 5 de marzo, en el mismo espacio se nos propuso que hiciéramos un juego en el cual pasáramos las llantas, un practicante seguido del otro, el primero haría un movimiento, el segundo lo imitaría y adicionaría otro, hasta pasar todos. Se trataba de un juego de memoria físico y mental, el último en pasar tenía que recordar los movimientos propuesto por todos. No es el espacio por sí solo, con las habilidades que vas adquiriendo se inventan cosas nuevas en cualquier tipo de espacio. Hay espacios que se prestan más porque tienen más obstáculos y hay otros que no tienen o tienen pocas cosas, entonces hay que adquirir más habilidades y más creatividad para desarrollar o combinar movimientos. (Notas de Campo, 2017)

Esta condición performativa se identificó en los escenarios del coliseo Alberto León Betancourt de la Universidad del Valle, el Parque 1 de Mayo y un espacio cercano al Muro de Parkour, los trazadores tienen un sitio físico que se han permitido modificar al utilizar módulos y llantas para lograr una "arquitectura precaria" que les suscite algunos trazos -usos alternativos del espacio-. En cuanto al Museo La Tertulia, este se convierte en un lugar de encuentro en el que pueden apreciar su arquitectura no solo como una edificación con cánones de "arte", sino como posibilidad de crear y realizar desplazamientos. La Liga de Gimnasia, en las observaciones, se convirtió en un lugar para realizar movimientos acrobáticos, no desde la disciplina y técnica que implica el gesto deportivo gimnástico, sino desde la circunstancia de realizar acrobacias para sobrepasar obstáculos. Quizás el único espacio cuya estructura cumple con un uso pensado desde lo concebido es el muro construido para la práctica del parkour dentro del Complejo Deportivo 
Alberto Galindo. No obstante, los ejemplos mencionados dan cuenta de que la práctica del espacio suscita otras formas de habitar la ciudad (foto 2). En este sentido, es posible comprender la tensión que surge de manera constante entre lo urbanístico y lo urbano, en el espacio practicado desde la creatividad de los trazadores que converge en un abanico de numerosos movimientos y usos parkour ${ }^{1}$, los cuales no son coherentes con el diseño preestablecido de los escenarios urbanos y son inmanentes a la relación que establecen los individuos con las formas urbanísticas construidas (arquitectura) desde su singularidad que se refleja en su preparación física y el desarrollo de diversas habilidades motrices.

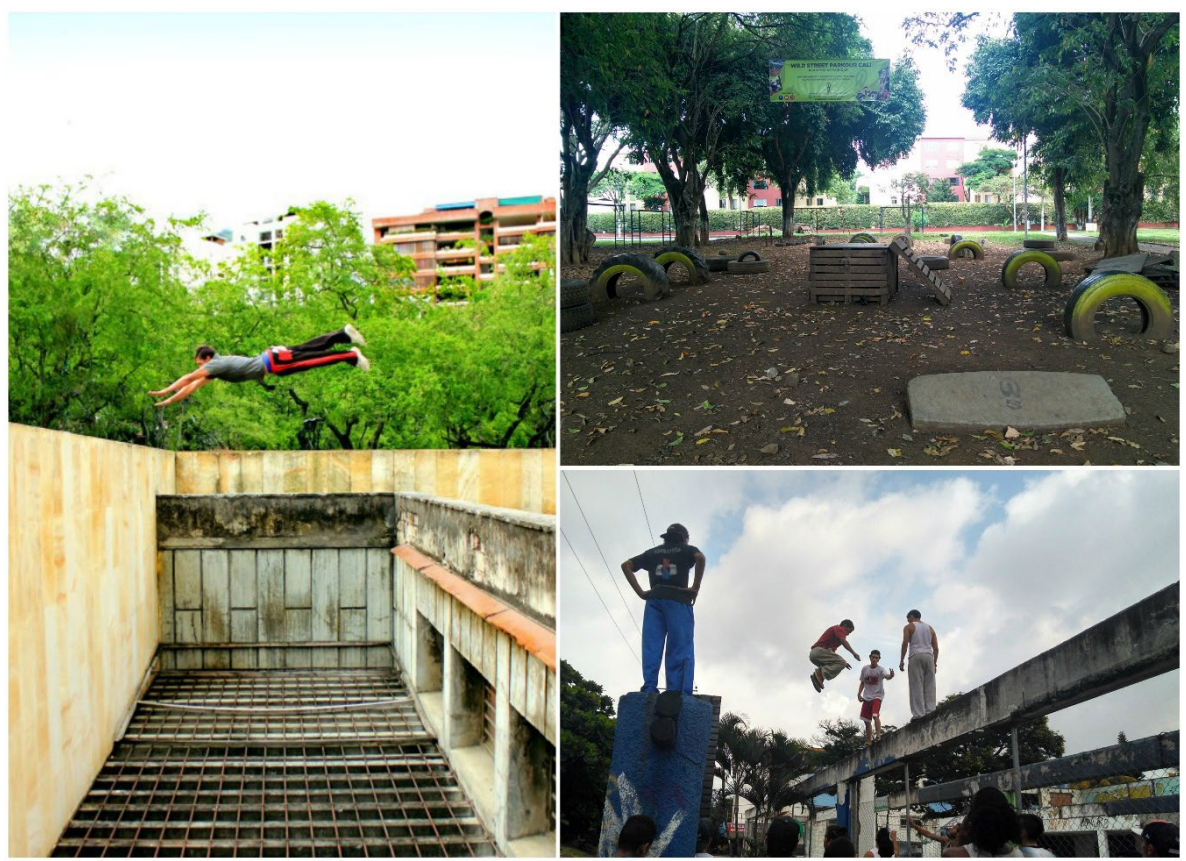

Foto 2. Espacio Percibido

Fuente: el autor

\footnotetext{
${ }^{1}$ En el trabajo de campo se reconocieron tres grupos de movimientos: a) Recepciones, utilizadas para distribuir la fuerza del impacto ocasionado por los saltos y el peso del practicante, generando un movimiento que minimice las lesiones físicas; b) Saltos, utilizados para sobrepasar obstáculos, de manera rápida y fluida; c) movimientos acrobáticos, retomados de otras prácticas como la gimnasia, la capoeira y el break dance.
} 
Es importante establecer una relación del parkour con los rituales de interacción en el espacio público. Goffman (1967) entiende lo ritual desde una perspectiva diferente a la de la antropología clásica, que vincula la noción con ceremonias religiosas, él la utiliza para referirse a las relaciones "cara a cara". Mencionado esto, los rituales de interacción en el espacio público de los escenarios observados se caracterizaron por ser en su mayoría de "interacciones no focalizadas" (Joseph, 1999a), en las que cada individuo se dedicaba a sus asuntos sin tener un foco de atención compartido; en el trabajo de campo esta condición fue más evidente en el Parque de los Estudiantes "Jovita", escenario que funciona como un lugar de paso y de múltiples interacciones: los ciudadanos vienen y van para la estación del trasporte masivo MIO, pasan motos, llegan jóvenes a la escalinata, se sientan y se juntan a conversar o consumir licor o sustancias psicoactivas. En este escenario realiza sus entrenamientos el grupo de practicantes de parkour conocido como Sifakas, interactuando en el espacio público como "unidades vehiculares" (Goffman, 1979) desde sus circulaciones, ejecutadas en diversos espacios en los que practican, porque incluso cuando se encuentran reunidos masivamente, en sus eventos como el entreno masivo o el Ajisie, consiguen evitar chocar unos con otros, teniendo una cooperación implícita que les permite mantenerse en movimiento. Cabe mencionar otra condición visible cuando se reúnen los practicantes de parkour su: "copresencia"; un ejemplo registrado fue en el entreno masivo, el cual en su sexta versión usó el Parque 1 de mayo, convocando gran cantidad de practicantes nacionales de parkour, propiciando que los trazadores fueran "unidades de participación" (Goffman, 1979) interactuando en los espacios públicos manteniendo por momentos atención visual y cognitiva, dando paso a algunas "interacciones focalizadas" (Joseph, 1999a). Ahora bien, la interacción de los trazadores y los múltiples usos que estos hacen del mobiliario urbano se desarrolla "ritualmente" siguiendo un orden específico observable como una rutina cotidiana en cada uno de sus encuentros. Para precisar con las notas de campo:

Un día de entrenamiento parkour puede describirse de la siguiente manera, ellos desarrollan una estructura organizativa, siguiendo un orden que inicia haciendo movimientos articulares, luego pasan a hacer ejercicios de calentamiento, gestos técnicos de Parkour, una distribución espacial de los practicantes y finalmente cierran la actividad con estiramientos y comentarios del entrenamiento. Este orden se ha evidenciado en los eventos y en el marco de los entrenamientos semanales agenciados por Sifakas y Wild Street. Se sugiere entonces que las acciones cotidianas de las actividades Parkour en el espacio público se ritualizan. (Notas de Campo, 2017) 


\section{El parkour y la apropiación simbólica de los espacios}

Sabemos que para Lefebvre (2013) existe el espacio vivido, el cual complementa los espacios concebido y percibido analizados en los párrafos anteriores. Este tercer momento espacial se relaciona con la representación y permite, que los ciudadanos sean "mucho más que un intérprete" (Joseph, 1988, p. 30), que exista la posibilidad de liberarse del espacio concebido, de "la tiranía del signo y de las imposiciones imaginarias del márquetin urbano" (Joseph, 1999b, p. 52). Para operacionalizar este espacio se buscó profundizar en las nuevas posibilidades de la realidad espacial que hacen los practicantes de parkour, a partir de sus voces, en sus relatos. Porque "el sentido de la vida social se expresa particularmente a través de discursos que emergen en la vida diaria, de manera informal, bajo la forma de comentarios, anécdotas, términos de trato y conversaciones" (Guber, 2011, p. 69). Es decir, la posibilidad de reconocer a los trazadores como usuarios que presentan "resistencia" y "creatividad" ante las ideas impuestas por el orden urbanístico. En este sentido, siguiendo a Lefebvre (1972) "en la escena espontánea de la calle yo soy a la vez espectáculo y espectador, y a veces, también, actor" (p. 14). En el trabajo de campo se identificó que los practicantes de parkour - en la espontaneidad y creatividad de los desplazamientos que realizan en los escenarios de la ciudad - hacen de la calle y del espacio público, espacios de representación. Una suerte de obra abierta en la que el "arte del desplazamiento", como también es nombrada la práctica, crea permanentemente el espacio. Se regresa de nuevo a notas de campo para precisar:

Estoy en el Entreno Masivo 6, en el Parque 1 de Mayo, a eso de las 2:00 pm, los espectadores superan las 100 personas, entre hombres, mujeres y niños... aplauden para motivar y dar apoyo a los trazadores, quienes ejecutan libremente movimientos, en el mobiliario urbano. Los aplausos al unísono se transforman en una suerte de ritual y "efervescencia social" (Durkheim, 1993). La dinámica de espectáculo que surgió hace que transeúntes y asistentes tomen fotografías o graben videos. La actividad se hizo durante más de media hora, fue un despliegue de diversas acrobacias en las que su cuerpo se transformó en un vehículo o performance corporal, porque propició una acción artística, o muestra escénica, en la que la improvisación, el asombro y la búsqueda de la estética eran protagonistas. (Notas de Campo, 2016)

A partir de este fragmento se sugiere que el Parkour apropia el espacio, tal como indica Lefebvre (2013): 
El grupo se apropia de un espacio natural modificado para servir a sus necesidades y posibilidades. La posesión (propiedad) sólo fue una condición y lo más a menudo una desviación de esta actividad «apropiativa» que alcanza su cima en la obra de arte (...) A menudo se trata de una construcción, de un monumento o de una edificación, pero no siempre es así: un sitio, una plaza o una calle pueden ser perfectamente considerados como espacios «apropiados». (pp. 213214)

De acuerdo con lo expresado, se identificó la "apropiación" con más fuerza en los eventos Entreno Masivo y Ajisie, agenciados por Sifakas y Wild Street, dos grupos, representantes del parkour en Cali, los cuales reúnen a los practicantes nacionales anualmente. Sentado esto, hay una oposición a la idea de propiedad relacionada con el espacio dominante, porque el espacio vivido permite "dominar" el espacio concebido. A pesar de que estas apropiaciones se dan de una manera que nombraremos como transitoria, en los trazos que ejecutan y en la instalación de módulos como los del Parque 1 de Mayo (Wild Park) y la Universidad del Valle (Move Park) el espacio público es el "ámbito por antonomasia del juego" (Delgado, 1999, p. 14). Es decir, la "volatilidad" del uso que hacen no impide que se propicien apropiaciones, las cuales producen resignificaciones del espacio público y en simultáneo ponen en tensión los significados que la planificación urbanística le atribuye a la calle, porque hay un aprovechamiento creativo de la ciudad en el que se dota de otros sentidos el mobiliario urbano. Respecto a esto, Mayol (1999) menciona:

Frente al conjunto de la ciudad, atiborrada de códigos que el usuario no domina pero que debe asimilar para poder vivir en ella, frente a una configuración de lugares impuestos por el urbanismo, frente a las desnivelaciones sociales intrínsecas al espacio urbano, el usuario consigue siempre crearse lugares de repliegue, itinerarios para su uso o su placer que son las marcas que ha sabido, por sí mismo, imponer al espacio urbano. (p. 10)

En otras palabras, los lugares de repliegue impuestos al espacio urbano en este documento son los distintos escenarios presentados, aquellos que han sido "apropiados" por los practicantes para el Parkour y son los referenciados para sus reuniones, eventos o trazos cotidianos. Para Walter Rodríguez, caleño de 31 años, que entrena desde hace doce años y es uno de los líderes de Sifakas, grupo reconocido como el primero en iniciar con el parkour en Cali, al hablar del uso de los espacios indica "los practicantes deberían procurar hacer con los espacios, no necesariamente ir a enterrar 
llantas o a construir (...) pero sí apropiarse del sitio donde esté entrenando para que la comunidad sepa que se hace algo que no es malo". Por su parte Diego López, caleño de 33 años, entrena desde hace diez años, menciona “el parkour es desplazarse por la parte urbana (...) cualquier cosa nos puede generar movimiento, cualquier murito pequeño que nos encontramos en la calle o un bolardo nos puede generar muchas cosas". Gabriela Camacho, caleña de 20 años, entrena desde hace tres años y medio, al preguntarle sobre su experiencia con el parkour indicó "cuando llego a esos espacios a entrenar, a saltar, es como que cambio de estado inmediatamente. Es decir, paso de estar mal a sentirme mejor, a estar en calma conmigo misma, pues son espacios que me ayudan a mí en la parte mental, como persona y en la parte física pues porque también voy a entrenar y fortalezco el cuerpo". En el caso de Jefferson Corrales, caleño de 19 años, entrena desde hace dos años y medio, al describir la manera de relacionarse con los espacios de la ciudad a través del parkour, menciona "al igual que al escribir si uno tiene muchas palabras empieza a usar más, es lo mismo en el movimiento (...) entonces entre más movimientos aprenda, más funcionalidad hay, más fluidez hay".

Aunque cada testimonio presenta una singularidad, posiblemente al preguntar a otros trazadores se identificarían cosas en común asociadas con la manera alternativa de relacionarse con el mobiliario urbano. Esto es, reconocer como los trazadores hacen "espacios diferentes, esos otros lugares, esas impugnaciones míticas y reales del espacio en el que vivimos" (Foucault, 2008, p. 43). Es decir, heterotopías dado el uso que propician de los escenarios y la calle, producen espacios heterogéneos que se proyectan sobre los espacios reales, como una suerte de contraespacios, aquellos "lugares que se oponen a todos los demás y que de alguna manera están destinados a borrarlos, compensarlos, neutralizarlos o purificarlos" (Foucault, 2008, p. 42). En otras palabras, frente a la planificación urbanista, las heterotopías logran el espacio vivido produciendo "otros espacios" sobre el espacio oficial. Por tanto, los muros, bancas, tubos, gradas, cualquier parte de la infraestructura de los escenarios utilizados se transforman (foto 3$)^{2}$. En clave de Goffman (1967), los rituales de interacción que hace el parkour en los espacios resignifican el "decorado" símbolos y significados en el intersticio de la ciudad concebida y percibida.

\footnotetext{
${ }^{2}$ Las fotografías dan cuenta del espacio vivido en clave de que representan una visión "desde dentro" de la práctica, en tanto los trazadores han intervenido las imágenes para enseñar lo significativo de sus desplazamientos en el espacio.
} 


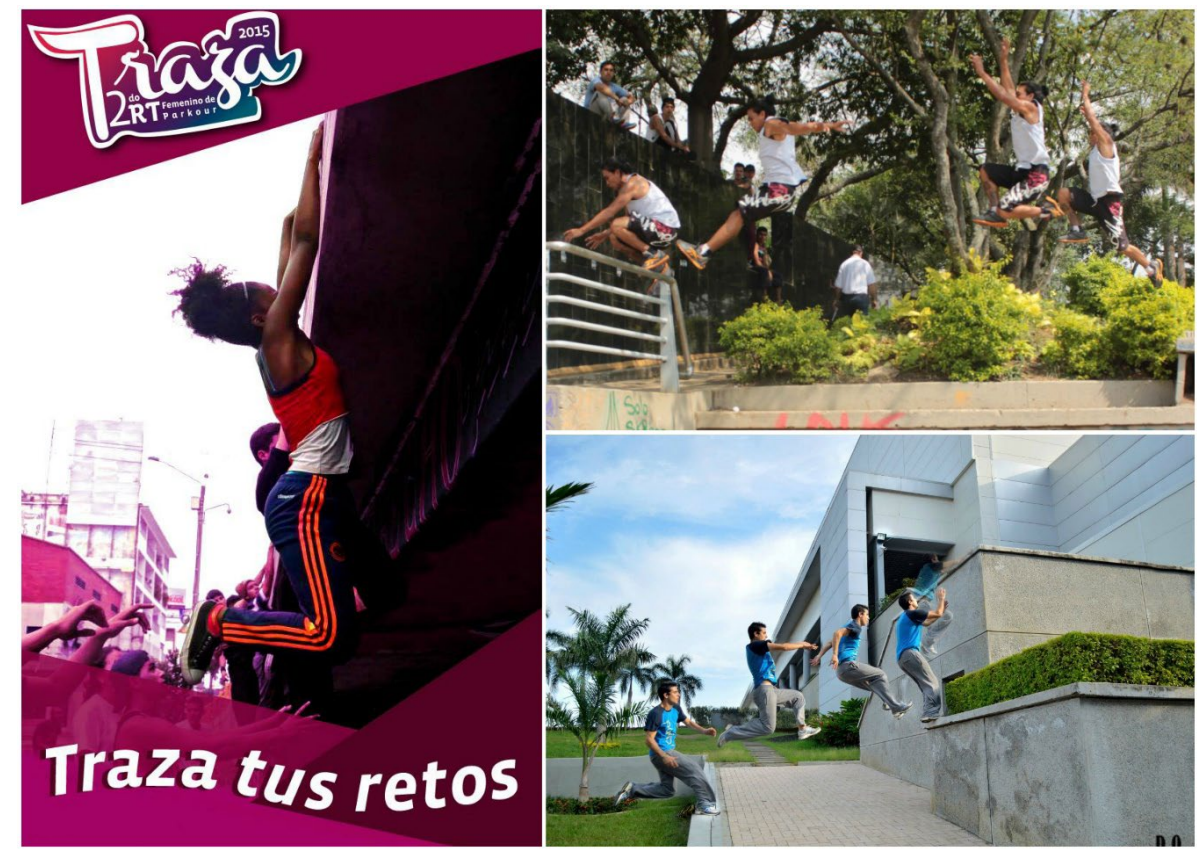

Foto 3. Espacio vivido Fuente: Facebook ${ }^{3}$.

Es por esto que los practicantes logran establecer un lazo afectivo con los escenarios que frecuentan que varía dependiendo de la singularidad de cada uno; además, es importante precisar en cómo ellos a partir de la realización del parkour logran un tipo de habitus, considerando que Bourdieu (2007) lo entiende como la gramática generativa de las prácticas, el sistema de disposiciones duraderas, producto de todas las experiencias pasadas, que se pueden transponer analógicamente para resolver otros problemas y asumir tareas enormemente diferenciadas, ya que constituyen una matriz de percepciones, apreciaciones, acciones. En tanto el habitus del parkour actúa como mediador entre el saber corporal y la acción o movimiento contingente por realizar en los diferentes espacios urbanos.

\footnotetext{
${ }^{3}$ 1. Foto de perfil Facebook Gabriela Reina, 27 de julio de 2015. Recuperado el 25 de febrero de 2019, de https://www.facebook.com/photo.php?fbid=837696856284050\&set=a.117715151615561\&type=3\&the ater. 2. Foto de Portada Facebook Jonathan Julio barrera, 9 de marzo del 2013. Recuperado de https:// www.facebook.com/photo.php?fbid=10200727789537887\&set=a.10200727606253305\&type=3\&theat er. 3. Foto de Portada Facebook Sebastián Mantilla, 4 de junio del 2013. Recuperado de https://www. facebook.com/photo.php?fbid=10201309237592292\&set=a.3976490090010\&type=3\&theater.
} 


\section{El parkour y la seguridad en la ciudad}

Recientemente en Colombia la palabra inseguridad, es una de las más mencionadas en los reportajes nacionales, para el caso de Cali, existen noticias ${ }^{4}$ que mencionan diversos modelos de delincuencia que van desde los robos de celulares hasta el homicidio. Sin embargo, una investigación que realizó el Observatorio de Políticas Públicas de la Universidad Icesi ${ }^{5}$ halló a partir de datos comparativos entre la percepción de seguridad y los hechos de inseguridad reales, que las personas que han sido víctimas de un hecho delictivo son una minoría. El coronel Henry Jiménez, de la Policía Metropolitana de Cali, mencionó que la percepción de inseguridad se debe a que quienes son víctimas de hurtos, le cuentan a un gran número de personas el hecho contagiando la sensación. El estudio también permitió identificar a las barras bravas como estructuras en las que se mueve el microtráfico de estupefacientes, armas, hurtos y homicidios.

Ahora bien, los practicantes de parkour también se pueden considerar como una comunidad que está estructurada de manera similar a las barras bravas. La sociedad contemporánea ha posibilitado la emergencia de diversos grupos tribales asociados a numerosas actividades como "los deportes de alto riesgo, el ecoturismo, los grandes festivales culinarios, sexuales, artísticos, musicales, los viajes exóticos, los programas televisivos de concurso" (Maffesoli, 1988, p. 8). Estas tienen la intencionalidad de luchar contra el aburrimiento y la desesperanza, a partir del codeo mutuo. Pero, a diferencia de las actividades delictivas que realizan las barras bravas, cuando se reúnen los practicantes de parkour en los escenarios de la ciudad propician que estos espacios "cambien" temporalmente, haciendo incluso que se perciban más seguros para ellos, sus acompañantes y demás ciudadanos. Esto se evidenció en los entrenamientos de "Parkour pa' la gente" en el Muro de Parkour y en el Parque de los Estudiantes "Jovita", lugares en los que es habitual encontrar consumo de drogas alucinógenas como la marihuana y percibir cierta inseguridad, que en lo práctico va más allá de la percepción, porque efectivamente son zonas inseguras de la ciudad; pero cuando los practicantes de parkour habitan estos espacios el ambiente se aprecia diferente. Se incluye un fragmento de las notas de campo, para precisar:

\footnotetext{
${ }^{4}$ Para mayor información consultar: http://www.elpais.com.co/noticias/inseguridad

${ }^{5}$ Información consultada en el diario El País de Cali del 14 de mayo del 2017. http://www.elpais.com.co/ judicial/por-que-los-calenos-se-sienten-mas-inseguros-de-lo-que-estan-en-realidad.html
} 
Estoy en el Muro de Parkour, necesito un registro fotográfico, sin practicantes, por ello he venido el domingo. Son aproximadamente las 12:00 m. Sin embargo, el espacio me propicia sensaciones diferentes a cuando he estado en los entrenamientos los sábados. De lejos, observo algunas personas que me generan sospecha. Me siento vulnerable, rápidamente saco mi celular, para tomar algunas fotografías del lugar y ágilmente me alejo trotando. (Notas de Campo, 2017)

En contraste, los practicantes de parkour mediante la apropiación física y simbólica propician una suerte de espacios seguros; como en el Parque 1 de Mayo, lugar que implementó con ayuda de la comunidad aledaña, una zona para la práctica como estrategia para recuperarlo del uso inadecuado de basuras y de la territorialización de los consumidores de sustancias psicoactivas. En este caso puntual se buscó que el cambio no fuese transitorio, sino que lograra trascender en el tiempo y en la actualidad ha presentado interesantes resultados, siendo un referente para la práctica en Cali. Se debe señalar además que el parkour permite a sus practicantes una manera de conocer la ciudad, porque generalmente están buscando nuevos lugares para trazar, situación que ayuda a resignificar el uso de ciertos espacios como los ya señalados y contribuye a largo plazo en el impacto de los imaginarios y percepciones de inseguridad. El parkour propicia un ambiente cordial en el que el respeto por el mobiliario y el otro son fundamentales. Habría que decir también que sus practicantes en ningún momento buscan conflicto con diferentes grupos urbanos, ni desplazarlos intencionalmente, por el contrario, sus relaciones se basan en la coexistencia a partir de "interacciones no focalizadas" (Joseph, 1999a).

\section{Reflexiones finales}

La investigación que originó este artículo hace parte de un esfuerzo orientado a pensar y examinar cómo las personas, en particular los practicantes de parkour de Cali, se las arreglan para producir el espacio social a partir de las representaciones, percepciones, vivencias, usos, significados y símbolos, que convergen en el habitar la ciudad. Como se ha mencionado, en este estudio se hace una aproximación a un tema novedoso usando de referente teórico para el análisis de las relaciones entre lo urbanístico y las personas en el espacio público, los tres momentos del espacio que desarrolló Lefebvre (2013) en La producción del espacio que dan cuenta de la interrelación de las nociones de espacio percibido, concebido y vivido. Con el análisis de esta trialéctica se aspiró a "sacar de las sombras" como el mismo Lefebvre (2013) señaló y hacernos a una comprensión más decantada de la 
convergencia de estas dimensiones en la producción del espacio social. En palabras de Beatriz Rendón (2008):

Se trata por tanto de valorar el espacio urbano, más que con el criterio de
funcionalidad arquitectónica, con el de la vivencialidad y apropiación
que este pueda propiciar a su potencial para ser incorporados de
manera sensible por el sujeto, es decir, como espacios articulados al
grupo social en que se inscriben. (p. 39)

Por ello, la investigación se orientó a captar lo "concreto" dado que como propuso Lefebvre (2013) la triada pierde su alcance si se le atribuye como "modelo abstracto". En este sentido, se identificaron los tres espacios en la información producida etnográficamente, contextualizando los diferentes escenarios en los recorridos desde lo urbanístico lo cual sugiere una idea más elaborada del significado de la ciudad, tanto para los que la viven como para aquellos que tienen el rol de planificarla y edificarla. Además, permitió hacer frente a aquellos estudios que ven en la concepción del espacio una planificación funcional que condiciona a sus habitantes en la cual, existe interés en la imposición de modelos que transmiten una determinada funcionalidad e imponen instrucciones sobre el uso y la interpretación del espacio público, generando en ocasiones la omisión de la diversidad de dinámicas sociales existentes.

A partir de lo desarrollado, se trató de ver en el espacio urbano las promesas ilimitadas de acción y experiencias de libertades individuales y colectivas que propician una tensión entre el diseño urbanístico y los usos emergentes que se hacen del espacio público. En otras palabras, desde el enfoque etnográfico se intentó interpretar la relación entre el entorno construido desde lo institucional y los trazadores que lo habitan como usuarios, para contrarrestar la idea de la naturalización originada en las "estructuras sociales convertidas en estructuras espaciales" (Bourdieu, 1999, p. 121). Se sugiere entonces que hoy como ayer, la planificación de la ciudad monopoliza y legitima expectativas del cómo se debe ser en el espacio público para un mejor vivir y bienestar de las personas. Pero debe ser claro que a pesar de la implantación urbanística los individuos habitan las ciudades al realizar diversas prácticas emergentes que están fuera del orden preestablecido y propician un flujo de usos, significados, símbolos, de lo que implica habitar la ciudad y producir el espacio social, lo cual remite a la afirmación de que "cada sociedad produce un espacio" (Lefebvre, 2013, p. 90).

El trabajo de campo permitió sugerir algunas respuestas, con relación a las posibilidades espaciales y sobre todo perfilar nuevas preguntas 
y desafíos en lo que respecta a la comprensión de la ciudad y las nuevas formas de habitarla, teniendo en cuenta que el uso de los espacios públicos es una cuestión central en la vida de cualquier ciudadano. Para terminar, es importante resaltar que este estudio accedió a una mayor comprensión de la relación existente entre el espacio público (urbano construido) y sus usuarios (trazadores) para dar cuenta de un espacio que se produce en la interdependencia de lo concebido, percibido y vivido, como único, es decir que la separación de la triada solo se hace con fines analíticos porque en la vida cotidiana los usuarios constantemente habitan la ciudad pasando de un espacio a otro, haciendo énfasis desde su singularidad; lo cual permite sugerir que este se produce socialmente en el resquicio, en su constante cambio.

\section{Referencias bibliográficas}

Balandier, G. (1994). El poder en escenas. De la representación del poder al poder de la representación. Barcelona, España: Paidós.

Bourdieu, P. (1999). Efectos de lugar. En P. Bourdieu, La miseria del mundo (pp. 119-124). Madrid, España: Akal.

Bourdieu, P. (2007). El sentido práctico. Buenos Aires, Argentina: Siglo XXI Editores.

Delgado, M. (1999). El animal público. Barcelona: Anagrama.

Durkheim, E. (1993). Las formas elementales de la vida religiosa. Madrid: Alianza.

Foucault, M. (2008). Topologías. Fractal, (48), 39-62. Recuperado de http://www.mxfractal. org/RevistaFractal48MichelFoucault.html.

Geertz, C. (1973). Descripción densa: hacia una teoría interpretativa de la cultura. En C. Geertz, La interpretación de las culturas (pp. 19-40). Barcelona, España: Gedisa S.A.

Goffman, E. (1967). Ritual de interacción. Buenos Aires: Editorial Tiempo Contemporáneo.

Goffman, E. (1979). Relaciones en público. España: Alianza Editorial.

Goffman, E. (1991). Los momentos y sus hombres (textos seleccionados y presentados por Yves Winkin). Barcelona, España: Paidós.

Guber, R. (2011). La etnografía, método, campo y reflexividad. Buenos Aires, Argentina: Siglo XXI Editores.

Hannerz, U. (1986). Exploración de la ciudad: hacia una antropología urbana. España: Fondo de Cultura Económica.

Joseph, I. (1988). El transeúnte y el espacio urbano. Argentina: Gedisa S.A.

Joseph, I. (1999a). Erving Goffman y la microsociología. España: Gedisa S.A.

Joseph, I. (1999b). Retornar a la ciudad el espacio público como lugar de acción. Colombia: Universidad Nacional de Colombia.

Lebreton, F., Routier, G. y Pardo, R. (2012). Deportes informales para conquistar los espacios urbanos. El caso de París. Gazeta de Antropología, 28(1), Recuperado de http://www. gazeta-antropologia.es/?p=77.

Lefebvre, H. (1972). La revolución urbana. Madrid, España: Alianza.

Lefebvre, H. (2004). Elementos de ritmo-análisis. New York: Continuum.

Lefebvre, H. (2013). La producción del espacio. España: Capitán Swing Libros.

Leyden, J. R. (2013). Parkour, Cuerpos que trazan heterotopías urbanas. Revista colombiana de Antropología, 49(2). Recuperado de http://www.scielo.org.co/pdf/rcan/v49n2/v49n2a03.pdf. 
Maffesoli, M. (1988). El tiempo de las tribus: El ocaso del individualismo en las sociedades posmodernas. México: Siglo XXI.

Mayol, P. (1999). La invención de lo cotidiano 2: habitar, cocinar. México: Universidad Iberoamericana.

MECEP. (2010). Manual de Diseño y Construcción de los Elementos Constitutivos del Espacio Público. Cali: Alcaldía de Santiago de Cali.

Park, R.E. (1999). La ciudad y otros ensayos de ecología urbana. España: Ediciones del Serbal.

Rendón, B. M. (2008). Espacios de ciudad y estilos de vida- El espacio público y sus apropiaciones. Recuperado de http://aprendeenlinea.udea.edu.co/: http://aprendeenlinea.udea.edu.co/ revistas/index.php/educacionfisicaydeporte/article/viewFile/2246/1807

Simmel, G. (2002 (1903)). La metropólis y la vida mental. En G. Simmel (ed.), Sobre la individualidad y las formas sociales (pp. 388-402). Quilmes: Universidad Nacional de Quilmes.

Wirth, L. (12 de 10 de 1988 (1938)). Antología de sociología urbana. Recuperado de https:// etnografiaurbana.files.wordpress.com: https://etnografiaurbana.wordpress.com/ 